\title{
PENGGUNAAN LAYANAN GRAB EXPRESS SEBAGAI JASA ANGKUTAN BARANG DENGAN SEPEDA MOTOR*
}

\author{
OLEH \\ Ni Putu Lilik Purnama Sari** \\ A.A. Sri Indrawati ${ }^{* * *}$ \\ Program Kekhususan Hukum Bisnis, Fakultas Hukum Universitas \\ Udayana
}

\begin{abstract}
Abstrak
Grab Express merupakan layanan untuk mengirim barang dengan moda transportasi roda dua (sepeda motor). Dalam perkembanganya Grab Express sebagai angkutan barang menimbulkan permasalahan terkait penggunaan sepeda motor sebagai alat angkutan barang. Hal tersebut memicu pertanyaaan tentang bagaimana pengaturan hukum layanan Grab Express dalam menyelenggarakan angkutan barang dengan sepeda motor dan bagaimana tanggung Jawab penyedia layanan grab express atas Kerusakan barang yang diterima oleh pengguna layanan Grab Express dengan sepeda motor.

Metode penelitian yang digunakan yaitu metode penelitian hukum normatif. Kesimpulan dari penulisan ini adalah Pengaturan hukum layanan Grab Express dalam menyelenggarakan angkutan barang dengan sepeda motor terdapat norma konflik antara PP No. 74 tahun 2014 tentang angkutan jalan Pasal 10 ayat (2) dengan UU No. 22 Tahun 2009 Tentang lalu Lintas dan Angkutan Barang Pasal Pasal 137 ayat (3). Dalam PP angkutan jalan ada pengecualian bahwa sepeda motor dapat digunakan sebagai alat angkutan barang apabila memenuhi persyaratan teknis. Namun dalam UULLAJ angkutan barang wajib menggunakan mobil barang. Dan untuk tanggung jawab apabila terjadi kerusakan barang yang terima oleh konsumen maka yang bertanggung jawab adalah mitra Grab dengan pemberian ganti rugi atau kompensasi.
\end{abstract}

Kata kunci: Grab Express, angkutan barang, pengaturan, tanggung jawab

\footnotetext{
* Karya Ilmiah ini merupakan di luar ringkasan skripsi

** Penulis pertama karya ini adalah Ni Putu Lilik Purnama Sari Mahasiswa Fakultas Hukum Universitas Udayana. Korespondensi: lilikpurnamasari98@gmail.com

${ }^{* * *}$ Penulis kedua karya ini adalah A.A. Sri Indrawati sebagai Dosen Fakultas Hukum Universitas Udayana
} 


\begin{abstract}
Grab Express is a service for sending goods with two-wheeled transportation (motorcycle). In its development, Grab Express as freight transport raises problems related to the use of motorbikes as a means of transporting goods. This triggered a question about how the legal arrangement of Grab Express services in carrying out goods transportation by motorbike and how the responsibility of grab express service providers for damage to goods received by users of Grab Express services on motorbikes.

The research method used is the normative legal research method. The conclusion of this paper is the legal arrangement of Grab Express services in carrying out goods transportation by motorcycle, there is a conflict norm between PP No. 74 of 2014 concerning road transport Article 10 paragraph (2) with Law No. 22 of 2009 concerning Goods Traffic and Transportation Article Article 137 paragraph (3). In road transport PP there are exceptions that motorbikes can be used as goods transportation if they meet technical requirements. But in UULLAJ freight transportation must use goods cars. And for liability in the event of damage to goods received by consumers, the responsible is Grab partners with compensation or compensation.
\end{abstract}

\title{
Keywords: Grab Express, freight transportation, regulation, responsible
}

\section{PENDAHULUAN}

\subsection{Latar Belakang}

Indonesia merupakan negara kepulauan yang memiliki beribu-ribu pulau berupa daratan dan sebagian besar perairan. Keadaan Indonesia yang begitu luas terdiri dari daratan, lautan dan udara memerlukan banyak pengangkutan yang bisa menjangkau keseluruhan wilayah Indonesia. ${ }^{1}$ Perkembangan di dunia transportasi dan komunikasi tidak lepas dari perkembangan ilmu pengetahuan dan teknologi. Dengan kemajuan ilmu pengetahuan dan teknologi ${ }^{2}$ maka akan semakin berkembang pula

\footnotetext{
${ }^{1}$ Abdulkadir Muhammad, 2013, Hukum Pengangkutan Niaga, PT Citra Aditya Bakti, Bandung, h.30

2 Andika Wijaya, 2016, Aspek Hukum Bisnis Trasnportasi Jalan Online, Sinar Grafika, Jakarta, h. 1
} 
inovasi yang muncul, semakin canggih dan maju tansportasi serta komunikasi di masyarakat. Di bidang transportasi salah satu contoh perkembangannya yaitu terkait pengangkutan orang dan Pengangkutan barang. Kebutuhan sarana transportasi terus akan mengalami peningkatan seiring dengan banyaknya permintaan untuk melakukan pengiriman barang dan perpindahan dari orang itu sendiri. Usaha yang dilakukan oleh perusahaan transportasi termasuk kegiatan perdagangan atau perniagaan.

Inovasi baru yang muncul di bidang transportasi yaitu adanya layanan Ojek online di Indonesia salah satunya seperti Grab. Kegiatan usaha yang dijalankan oleh Grab meliputi pelayanan atau jasa seperti Grab Taxi, Grab Food, Grab Car, Grab Bike, Grab Express dan sebagainya dengan mekanisme online. Hanya menggunakan smartphone setiap orang bisa menggunakan jasa tersebut melalui pemesanan dengan waktu yang cukup singkat. Salah satu layanan untuk pengangkutan barang yaitu Grab Express. Grab Express sebagai transportasi online dengan menggunakan sepeda motor sebagai moda pengangkutan. Layanan Grab Express sangat menarik karena pengiriman barang berupa paket dan dokumen dari tempat asal dan penerimaan barang pada saat hari itu juga. Dalam memilih jasa pengangkutan barang, masyarakat akan menilai dari factor kualitas jasa transportasi barang yang efektif dan efisienDalam hal ini Efektif berarti selamat, nyaman, aksesibilitas tinggi, terpadu, lancar dan cepat, mudah dicapai, tepat waktu, aman. Efisien berarti tarif terjangkau atau murah. ${ }^{3}$

3 Putu Yuni Riswanty, "Batas Kewenangan Penyidik Pegawai Negeri Sipil dan Kepolisian Dalam Penindakan Pelanggaran Lalu Lintas dan Angkutan Jalan", Jurnal Magister Hukum Udayana, Vol. 02, No. 01, Januari 2013, h. 2, URL : https://ojs.unud.ac.id/index.php/jmhu/article/view/4443/3363, diakses pada tanggal 21 Mei 2019. Pukul 20.17 WITA 
Hadirnya layanan Grab Express sebagai jasa angkutan barang yang mengantarkan barang secara cepat dan diterima pada saat hari yang sama. Seiring dengan perkembangnya layanan Ojek online seperti Grab Express masih menimbulkan permasalahan di berbagai kalangan di masyarakat karena menyangkut sah atau tidaknya Grab sebagai jasa angkutan barang. Grab sebagai alat transportasi dipandang tidak sesuai dengan peraturan pengangkutan. Karena kendaraan sepeda motor bukan sebagai kendaraan bermotor umum. Selain itu Grab Express sebagai jasa angkutan barang kadang-kadang akan menimbulkan kekecewaan terhadap konsumen atas barang yang diterimanya seperti adanya kerusakan dan hilang. Hal ini akan membuat konsumen atau pengguna jasa angkutan untuk menuntut ganti rugi kepada Grab Express.

\subsection{Rumusan Masalah}

Berdasarkan latar belakang masalah diatas tersebut, maka dapat dirumuskan permasalahan sebagai berikut

1. Bagaimana pengaturan hukum layanan Grab Express dalam menyelenggarakan angkutan barang dengan sepeda motor

2. Bagaimana tanggung jawab penyedia layanan Grab Express atas kerusakan barang yang diterima oleh pengguna layanan Grab Express dengan sepeda motor

\subsection{Tujuan Penulisan}

Tujuan dari penulisan ini untuk mengetahui Pengaturan hukum layanan Grab Express dalam menyelenggarakan angkutan Barang dengan Sepeda Motor dan Tanggung Jawab penyedia 
layanan grab express atas Kerusakan barang yang diterima oleh pengguna layanan Grab Express dengan sepeda motor

\section{ISI MAKALAH}

\subsection{Metode Penelitian}

Metode penelitian dalam karya ini adalah penelitian Hukum Normatif yaitu penelitian hukum yang sumber datanya hanyalah data primer dan data sekunder. ${ }^{4}$ Pendekatan penelitian ini yaitu pendekatan peraturan perundang-undangan. Bahan hukum yang digunakan yaitu Bahan hukum Primer dan sekunder. Bahan Hukum Primer adalah bahan hukum yang bersifat autoritatif artinya mempunyai otoritas ${ }^{5}$ seperti peraturan perundangundangan yang berkaitan dengan pokok pembahasan. Bahan hukum sekunder adalah bahan hukum yang memberikan penjelasan mengenai bahan hukum primer seperti buku-buku, dan jurnal-jurnal yang berkaitan dengan pokok pembahasan.

\subsection{Hasil dan Pembahasan}

\subsubsection{Pengaturan Hukum Layanan Grab Express Dalam Menyelenggarakan Angkutan Barang Dengan Sepeda Motor}

Pengangkutan merupakan bagian dari masyarakat yang berperan penting dalam mendukung proses pemindahan barang dan atau jasa. Pengangkutan adalah perjanjian timbal balik antara pengangkut dengan pengirim, dimana mampu mengikatkan diri untuk mengadakan perpindahan barang dan/atau orang dari satu titik tempat ke tempat tujuan tertentu dengan keadaan

\footnotetext{
4 Amiruddin dan Zainal Asiki, 2012, Pengantar Metode Penelituan Hukum, PT.RajaGrafindo Persada, Jakarta, h. 118.

${ }^{5}$ Peter Mahmud Marzuki, 2009, Penelitian Hukum, Kencana, Jakarta, h. 141
} 
seperti semula. ${ }^{6}$ Berdasarkan Undang-Undang Nomor 22 Tahun 2009 Tentang Lalu Lintas \& Angkutan Jalan (selanjutnya disingkat dengan UULLAJ) Pasal 1 angka 3 angkutan adalah proses perpindahan orang dan atau barang dari satu tempat ke tempat lain dengan memakai kendaraan. Penyelenggaraan angkutan baik orang maupun barang menggunakan kendaraan bermotor dijalan bertujuan untuk tercapainya standar pelayanan minimal seperti keselamatan, kesetaraan kenyamanan, keterjangkauan, keteraturan dan keamanan di jalan. Ditinjau dari segi kegunaan, pengangkutan dibagi menjadi dua ialah pengangkutan untuk tujuan usaha disebut pengangkutan umum dan pengangkutan tidak dilakukan untuk tujuan usaha.

Pengangkutan pada umumnya berfungsi untuk membawa dan memindahkan barang menggunakan suatu kendaraan sebagai alat trasportasi. Pada Pasal 47 UULLAJ kendaraan meliputi kendaraan bermotor dan kendaraan tidak bermotor. Jenis dari kendaraan bermotor yaitu mobil bus, mobil penumpang, mobil barang, sepeda motor dan kendaraan khusus. Kendaraan Bermotor seperti mobil bus, mobil barang, dan mobil penumpang di kelompokkan berdasarkan fungsinya yaitu kendaraan bermotor perseorangan dan umum.

Perkembangan teknologi yang begitu pesat banyak ide kreatif yang bermunculan di bidang pengangkutan yang sesuai dengan keinginan masyarakat. Salah satu bentuk dari Ojek Online yaitu Grab yang layanannya seperti Grab Express. Grab Express merupakan layanan kurir ekspres atau pengantaran barang7 dapat diakses secara online melalui aplikasi yang bisa diunduh di

\footnotetext{
${ }^{6}$ Andika Wijaya, op.cit. h. 169

${ }^{7}$ Dina Kusuma Ratih dan Hilda Yunita sabrie, 2018, "Pengiriman Paket Menggunakan Grab Express Beserta Bentuk Pertanggungjawabannya", Volume 2 Issue 2, September 2018, h. 462, URL: http://ojs.uho.ac.id/index.php/holrev/article/view/4348, diakses pada tanggal 28 April 2019, Pukul 09.10 WITA.
} 
smartphone. Grab Express sebagai jasa angkutan barang dengan moda transportasi sepeda motor dikendarai oleh mitra grab. Dengan penawaran yang diberikan oleh Grab Express dan harganya relative murah, aman, nyaman, serta cepat. Hal ini akan manarik minat masyarakat untuk menggunakan jasa Grab express untuk mengirim barang.

Grab Express sebagai pengangkut barang melalui kurir dengan alat angkut sepeda motor memberikan kemudahan kepada konsumen, namun Grab Express mengangkut barang dengan sepeda motor dianggap tidak sesuai dengan peraturan pengangkutan. Berdasarkan Pasal 47 ayat (3) UULLAJ bahwa sepeda motor bukan sebagai kendaraan bermotor perseorangan maupun kendaraan bermotor umum. UULLAJ Pasal 137 ayat (2) dan ayat (3) bahwa sepeda motor hanya digunakan sebagai alat untuk angkutan orang dan jika untuk angkutan barang wajib dengan mobil barang. Mobil barang sebagian atau keseluruhan di rancang untuk mengangkut barang. Jadi dapat disimpulkan bahwa Grab Express dalam pelaksanaannya mengangkut barang dengan sepeda motor bukan sebagai alat untuk pengangkut barang yang sah.

Namun jika dilihat pengaturan Grab Express sebagai jasa angkutan barang dengan menggunakan sepeda motor di Peraturan Pemerintah Nomor 74 Tahun 2014 tentang Angkutan Jalan (PP Angkutan Jalan) pada Pasal 10 ayat (2) dimana sepeda motor bisa dipakai sebagai alat angkut barang jika persyaratan teknis terpenuhi. Persyaratan teknis diatur pada Pasal 10 ayat(4) yaitu lebar muatan tidak melebihi stang pengemudi, tidak melebihan 900 (Sembilan ratus) millimeter untuk tinggi muatan dan diletakkan di belakang pengemudi. Angkutan barang dengan sepeda motor harus memperhatikan keselamatan. Untuk 
menjamin penyelenggaraan lalu lintas dan angkutan jalan memenuhi standar keselamatan. Jadi berdasarkan PP Angkutan Jalan maka Grab Express dalam memberikan layanan angkutan barang menggunakan sepeda motor tidak bertentang dengan peraturan pemerintah yang ada asalkan memenuhi persyaratan teknis. Grab Express memberlakukan pembatasan ukuran barang yang dikirim dengan sepeda motor sebagai alat angkutan barang hal ini sejalan dengan PP No. 74 Tahun 2014. Ukuran barang yang dapat dikirim melalui layanan Grab Express Maksimal 25 x 32 x $12 \mathrm{~cm}$ dan beratnya maksimal 5 kilogram.

Dengan adanya PP Angkutan Jalan bertentang dengan UULLAJ, dimana sudah jelas meyebutkan bahwa sepeda motor bukan sebagai alat untuk angkutan barang dan harus menggunakan mobil barang tetapi dalam PP angkutan jalan menyebutkan sepeda motor sebagai alat angkutan barang apabila memenuhi persyaratan teknis. Dan di pertegas dengan Keluarnya Surat Pemberitahuan yang ditandatangani oleh Menteri Perhubungan Nomor: UM.3012/1/21/PBH/2015 tanggal 9 november $2015^{8}$ dilatar belakangi dengan adanya permasalahan terkait transportasi online roda dua dianggap sebagai angkutan tanpa izin atau liar sehingga adanya larangan dari pemerintah dengan dikeluarkannya surat tersebut.

Jadi berdasarkan asas Lex superior derogate lex inferior artinya peraturan perundang-undangan yang lebih tinggi akan mengesampingkan peraturan yang lebih rendah. Sesuai dengan hierarki peraturan perundang-undangan di Indonesia bahwa UULLAJ lebih tinggi kedudukannya dari pada PP tentang Angkutan jalan maka aturan yang digunakan yaitu UULLAJ. Berdasarkan UULLAJ Grab Express sebagai layanan angkutan

\footnotetext{
${ }^{8}$ Andika Wijaya, op.cit. h.4
} 
barang dengan sepeda motor tidak sesuai dengan peraturan yang ada. Karena sepeda motor hanya sah sebagai alat untuk mengangkut orang. Dan angkutan barang harus menggunakan mobil barang. Dewasa ini kebutuhan roda dua sebagai alat transportasi jalan online diperlukan dalam masyarakat. Oleh karena itu pengaturan sepeda motor sebagai jasa angkutan barang perlu diperjelas lagi. Sehingga dapat menguntungkan banyak pihak dan juga dapat melindungi konsumen sebagai pengguna layanan Grab Express sebagai angkutan barang.

\subsubsection{Tanggung Jawab Penyedia Layanan Grab Express Atas Kerusakan Barang Yang Diterima Oleh Pengguna Layanan Grab Express Dengan Sepeda Motor}

Dalam hukum perlindungan Konsumen Prinsip tentang tanggung jawab merupakan perihal yang begitu penting. ${ }^{9}$ Prinsip pertanggung jawaban hukum pengangkutan ada tiga yaitu 10

a. Tanggung jawab karena kesalahan, kesalahan dari setiap pengangkut dalam penyelenggaraan pengangkutan harus bertanggung jawab membayar segala kerugian yang timbul akibat kesalahanya itu.

b. Tanggung jawab karena praduga, pengangkut bertanggung jawab setiap kerugian yang disebabkan oleh pengangkutan yang diselenggarakan.

c. Tanggung jawab mutlak, pengangkut bertanggung jawab setiap kerugian yang timbul dengan tidak harus melakukan pembuktian ada tidaknya kesalahan pengangkut.

Dalam melaksanakan pengangkutan, tanggung jawab dari pengangkut atas keselamatan dan keamanan barang yang dikirim

${ }^{9}$ Celina, Celina Tri Siwi Kristiyanti, 2011, Hukum Perlindungan Konsumen, Sinar Grafika, Jakarta, h. 92

${ }^{10}$ Abdulkadir Muhammad, op.cit, 43 
melalui layanan Grab Express. Berdasarkan Undang-Undang Nomor 8 Tahun 1999 Tentang Perlindungan Konsumen (selanjutnya disebut UUPK) Pasal 4 telah menetapkan salah satu hak dari konsumen untuk mendapatkan keselamatan dan keamanan barang yang dikirim melalui layanan Grab Express

Mengenai Tanggung jawab terhadap kerusakan barang melalui layanan Grab Express yang bertanggung jawab yaitu mitra kerja atau pengangkut karena pada Grab Indonesia, Perusahaan tidak bertanggung jawab pada kelalaian atau tindakan apapun yang dilakukan oleh penyedia transportasi.

Jika terjadi kerusakan barang berdasarkan Pasal 19 ayat (1) dan (2) UUPK dimana pelaku usaha bertanggung jawab untuk mengganti rugi atas kerusakan barang yang diterima oleh pengguna layanan Grab Express. Ganti rugi yang dimaksud berupa penggantian barang. Jadi ketika adanya kerusakan yang diterima oleh konsumen atas barangnya, maka yang harusnya bertanggung jawab yaitu Mitra Grab atau pengangkut. Tanggung jawab yang dilakukan oleh mitra Grab merupakan tanggung jawab mutlak karena menjual jasa untuk mengirim barang. Dengan mengganti kerugian atas kerusakan barang yang dialami konsumen pada dasarnya berfungsi sebagai:

a. Untuk melakukan pemulihan atas hak-hak konsumen yang dilanggar

b. Untuk melakukan Pemulihan atas kerugian yang diderita konsumen baik materiil maupun Immateriil

c. Untuk melakukan Pemulihan kondisi barang seperti semula ${ }^{11}$

Mengenai barang yang diangkut yang mengalami kerusakan UULLAJ pada Pasal 193 mengenai tanggung jawab perusahaan

${ }^{11}$ Adrian Sutedi, 2008, Tanggung Jawab Produk dalam Hukum Perlindungan Konsumen, Ghalia Indonesia, Bogor,h. 58 
angkutan umum atas kerusakan barang akibat penyelenggaraan angkutan dan untuk perhitungan ganti rugi harus di ganti sesuai dengan nyata-nyata dialami oleh pengirim. Jadi Pengangkut atau Mitra Grab Express bertanggung jawab atas kerugian yang diderita konsumen. Secara normal, konsumen telah diberikan perlindungan hukum dalam bentuk ganti rugi jika terjadinya kerusakan barang yang dikirim. ${ }^{12}$

\section{PENUTUP}

\subsection{Kesimpulan}

Dari hasil analisis dan pembahasan tersebut maka dapat disimpulkan bahwa:

1. Pengaturan hukum mengenai layanan Grab Express sebagai angkutan barang menggunakan sepeda motor terdapat di PP Angkutan Jalan Pasal 10 ayat (2) apabila sepeda motor memenuhi persyaratan teknis. Tetapi penyelenggara angkutan barang dengan sepeda motor melalui Grab Express tidak sesuai dengan UULLAJ karena Pasal 137 ayat (3) UULLAJ untuk angkutan barang harus menggunakan mobil barang dan sepeda motor hanya sah untuk mengangkut orang.

2. Tanggung jawab atas kerusakan barang yang diterima konsumen maka yang bertanggung jawab yaitu pengangkut atau mitra grab. Pada Pasal 19 UUPK mitra grab bertanggung jawab untuk memberikan ganti rugi atau kompensasi.

${ }^{12}$ Ronald Saij, 2016, Penyalahgunaan Keadaan Oleh Negara Dalam Praktik Perjanjian Pada Kajian Hukum Privat, Volume 38, Nomor 3, Desember 2016, h. 188-189, URL: https://ojs.unud.ac.id/index.php/kerthapatrika/article/view/30080/18451, diakses pada tanggal 30 Mei 2019, Pukul 07. 53 WITA. 


\subsection{Saran}

1. Hendaknya Pengaturan hukum penyelenggaraan angkutan barang dengan sepeda motor pada PP Nomor 74 Tahun 2014 tentang Angkutan Jalan harus sesuai dengan UU No. 22 Tahun 2009 tentang Lalu Lintas dan Angkutan Jalan agar memberikan kepastian hukum untuk masyarakat.

2. Hendaknya pelaku usaha mengganti kerugian atas kerusakan barang sesuai dengan nilai ekonomis suatu barang.

\section{DAFTAR PUSTAKA}

Abdulkadir Muhammad, 2013, Hukum Pengangkutan Niaga, PT Citra Aditya Bakti, Bandung.

Adrian Sutedi, 2008, Tanggung Jawab Produk dalam Hukum Perlindungan Konsumen, Ghalia Indonesia, Bogor.

Andika Wijaya, 2016, Aspek Hukum Bisnis Trasnportasi Jalan Online, Sinar Grafika, Jakarta.

Amiruddin dan Zainal Asiki, 2012, Pengantar Metode Penelituan Hukum, PT.RajaGrafindo Persada, Jakarta.

Celina Tri Siwi Kristiyanti, 2011, Hukum Perlindungan Konsumen, Sinar Grafika, Jakarta.

Peter Mahmud Marzuki, 2009, Penelitian Hukum, Kencana, Jakarta.

\section{JURNAL}

Dina Kusuma Ratih dan Hilda Yunita sabrie, 2018, "Pengiriman Paket Menggunakan Grab Express Beserta Bentuk Pertanggungjawabannya", Halu Oleo Law Review, Volume 2 Issue $2, \quad$ September 2018 URL: http://ojs.uho.ac.id/index.php/holrev/article/view/4348, diakses pada tanggal 28 April 2019. Pukul 09.10 WITA.

Ronald Saij, 2016, Penyalahgunaan Keadaan Oleh Negara Dalam Praktik Perjanjian Pada Kajian Hukum Privat, Volume 38, 
Nomor 3, Desember 2016, URL: https://ojs.unud.ac.id/index.php/kerthapatrika/article/vie w/30080/18451, diakses pada tanggal 30 Mei 2019. Pukul 07. 53 WITA.

Putu Yuni Riswanty, "Batas Kewenangan Penyidik Pegawai Negeri Sipil dan Kepolisian Dalam Penindakan Pelanggaran Lalu Lintas dan Angkutan Jalan", Jurnal Magister Hukum Udayana, Vol. 02, No. 01, Januari 2013,URL : https://ojs.unud.ac.id/index.php/jmhu/article/view/4443/ 3363, diakses pada tanggal 21 Mei 2019. Pukul 20.17 WITA

\section{PERATURAN PERUNDANG-UNDANGAN}

Undang-Undang Nomor 8 Tahun 1999 tentang Perlindungan Konsumen (Lembaran Negara Republik Indonesia Tahun 1999 Nomor 42 Tambahan Lembaran Negara Republik Indonesia Nomor 3821)

Undang-Undang Nomor 22 Tahun 2009 tentang Lalu Lintas dan Angkutan Jalan (Lembaran Negara Republik Indonesia Tahun 2009 Nomor 96, Tambahan Lembaran Negara Republik Indonesia Nomor 5025)

Peraturan Pemerintah Nomor 74 Tahun 2014 tentang Angkutan Jalan (Lembaran Negara Republik Indonesia 2014 Nomor 260 Tambahan Lembaran Negara Republik Indonesia Nomor 5594) 